\title{
Article \\ Early Nutritional Intervention to Promote Healthy Eating Habits in Pediatric Oncology: A Feasibility Study
}

\author{
Véronique Bélanger ${ }^{1,2} \oplus$, Josianne Delorme ${ }^{1,2} \oplus$, Mélanie Napartuk ${ }^{1,2} \oplus$, Isabelle Bouchard ${ }^{2}$, Caroline Meloche ${ }^{2}$, \\ Daniel Curnier ${ }^{2,3}$, Serge Sultan ${ }^{2,4,5}$, , Caroline Laverdière ${ }^{5,6}$, Daniel Sinnett ${ }^{2,6}$ and Valérie Marcil ${ }^{1,2, *}$ \\ 1 Department of Nutrition, Université de Montréal, Montreal, QC H3T 1A8, Canada; \\ v.belanger.7@gmail.com (V.B.); josianne.delorme@umontreal.ca (J.D.); melanie.napartuk@umontreal.ca (M.N.) \\ 2 Research Centre, CHU Sainte-Justine, Montreal, QC H3T 1C5, Canada; \\ isabelle.bouchard.hsj@ssss.gouv.qc.ca (I.B.); cmeloche.hsj@gmail.com (C.M.); \\ daniel.curnier@umontreal.ca (D.C.); serge.sultan@umontreal.ca (S.S.); daniel.sinnett@umontreal.ca (D.S.) \\ 3 School of Kinesiology and Physical Activity Sciences, Université de Montréal, Montreal, QC H3T 1J4, Canada \\ 4 Department of Psychology, Université de Montréal, Montreal, QC H2V 2S9, Canada \\ 5 Division of Hematology-Oncology, CHU Sainte-Justine, Montreal, QC H3T 1C5, Canada; \\ caroline.laverdiere@umontreal.ca \\ 6 Department of Pediatrics, Université de Montréal, Montreal, QC H3T 1C5, Canada \\ * Correspondence: valerie.marcil@umontreal.ca; Tel.: +1-514-345-4931 (ext. 3272)
}

\section{check for}

updates

Citation: Bélanger, V.; Delorme, J.; Napartuk, M.; Bouchard, I.; Meloche, C.; Curnier, D.; Sultan, S.; Laverdière, C.; Sinnett, D.; Marcil, V. Early Nutritional Intervention to Promote Healthy Eating Habits in Pediatric Oncology: A Feasibility Study. Nutrients 2022, 14, 1024. https:// doi.org/10.3390/nu14051024

Academic Editor: Peter

Meade Anderson

Received: 15 January 2022

Accepted: 24 February 2022

Published: 28 February 2022

Publisher's Note: MDPI stays neutral with regard to jurisdictional claims in published maps and institutional affiliations.

Copyright: (C) 2022 by the authors. Licensee MDPI, Basel, Switzerland. This article is an open access article distributed under the terms and conditions of the Creative Commons Attribution (CC BY) license (https:// creativecommons.org/licenses/by/ $4.0 /)$.

\begin{abstract}
This study aims to describe the feasibility of a nutritional intervention that promotes healthy eating habits early after cancer pediatric diagnosis in patients and their parents. Participants were recruited 4 to 12 weeks after cancer diagnosis as part of the VIE study. The one-year nutritional intervention included an initial evaluation and 6 follow-up visits every 2 months with a registered dietician. The feasibility assessment included rates of retention, participation, attendance, completion of study measures, and participants' engagement. A preliminary evaluation of the intervention's impact on the participants' dietary intakes was conducted. A total of 62 participants were included in the study $(51.6 \%$ male, mean age $=8.5$ years, mean time since diagnosis $=13.2$ weeks). The retention and attendance rates were $72.6 \%$ and $71.3 \%$, respectively. Attendance to follow-up visits declined over time, from $83.9 \%$ to $48.9 \%$. A majority of participants had high participation (50.8\%) and high engagement $(56.4 \%)$. Measures of body-mass-index or weight-for-length ratio and dietary 24 -h recalls were the procedures with the highest completion rates. Participants with refractory disease or relapse were less likely to complete the intervention. Post-intervention, participants $(n=21)$ had a lower sodium intake compared to the initial evaluation. These results suggest that a nutritional intervention that involves patients and parents early after a pediatric cancer diagnosis is feasible.
\end{abstract}

Keywords: childhood cancer; feasibility study; nutritional intervention; acute treatment phase

\section{Introduction}

In Canada, cancer remains the leading cause of death from disease in children and adolescents despite an almost $85 \%$ survival after 5 years [1,2]. Yet, childhood cancer survivors (CCS) are at a high risk of suffering from chronic health problems even as young adults $[3,4]$, including cardiometabolic (CM) complications [5-7]. It is therefore recommended that CM parameters be closely monitored in children and adolescents who have been treated for cancer. Thus, both the American Heart Association (AHA) and the Children's Oncology Group recommend the screening of blood pressure, blood lipids, glucose metabolism parameters, and body weight at the end of cancer treatment and to monitor their evolution yearly [8,9]. Moreover, like the general population, better healthy eating habits in CCS have been associated with better body fat parameters and CM health [10-12]. Therapeutic interventions for CCS presenting CM complications such as high body mass index (BMI), high blood pressure, and high LDL-C include the promotion of healthy lifestyle habits [8]. 
However, adopting healthy lifestyle habits as an adult can sometimes be challenging, and implanting them at an early age is undeniably a good strategy.

Traditionally, nutritional and dietary intervention during cancer treatment in children and adolescents has been aimed at preventing or improving malnutrition $[13,14]$. The presence of malnutrition at diagnosis or during treatments has been associated with a lower tolerance to therapy, increased risk of infections, and worse outcomes [15-17]. The causes leading to poor nutritional status during pediatric cancer are multifactorial. Not only is cancer itself characterized as a state of metabolic stress that can lead to undernutrition, but treatments cause various pernicious digestive side effects such as dysgeusia, mucositis, nausea, vomiting, and diarrhea [13,14,18,19]. Dyslipidemia [20,21], glucose intolerance [22], high blood pressure [23], and an increase in BMI [18] are also acute side effects of cancer treatments. However, they have been poorly addressed by nutritional intervention during pediatric cancer therapy. A high BMI and obesity at diagnosis is another form of malnutrition associated with an increased risk of complications (i.e., wound infection and arterial thrombosis) [24] and, in acute lymphoblastic leukemia (ALL), of disease relapse [25].

Although obesity at diagnosis and increased BMI during treatment have been associated with CM complications in CCS [26,27], most of the nutritional interventions during pediatric cancer treatment have not considered the long-term impact of therapy. However, it has been proposed that patients should be educated about the importance of healthy eating and regular physical activity during cancer treatment [28-31]. The few lifestyle interventions for preventing long-term CM complications were developed solely for childhood ALL and implemented at the remission or maintenance phases [29,30,32,33]. Implementing such interventions early after cancer diagnosis brings challenges, given the significant medical, emotional, and financial difficulties encountered. Feasibility studies provide an opportunity to preliminarily assess the capacity to implement an intervention and its impact [34]. By documenting recruitment capacity, assessing intervention acceptability, and collecting study measures, these studies provide a flexible methodology that can be adapted during its course [34-36].

We propose that a nutritional intervention that begins shortly after diagnosis and involves patients and their parents is feasible. Here, we aim to describe the feasibility of a nutritional intervention promoting healthy eating habits early after cancer diagnosis and to investigate the relationships between feasibility data and participants' characteristics (socio-demographic, cancer-related, and dietary intakes at the initial visit). Our secondary objective is to preliminary assess the impact of the intervention on participants' dietary intakes.

\section{Materials and Methods}

\subsection{Study Framework and Ethics}

This work is part of the VIE (Valorization, Implication, Education) multidisciplinary study that consists of nutritional, psychological, and physical activity interventions at CHU Sainte-Justine (CHUSJ) in Montreal, QC, Canada. The VIE program aims at supporting and educating children diagnosed with cancer and their parents about healthy lifestyle habits to prevent short- and long-term health complications. The design of the physical activity and psychosocial interventions have been described in detail elsewhere [37,38]. The study was approved by the Ethics Review Committee of CHU Sainte-Justine (\#2017-1413) and was in accordance with the Declaration of Helsinki.

\subsection{Participants}

Participants were recruited from February 2018 to December 2019. Inclusion criteria were: (1) being 21 years old or younger at diagnosis; (2) being treated with chemotherapy or radiotherapy; and (3) being able to give informed consent (by parents or legal guardians). The agreement of the attending oncologist was required for the participation of eligible patients. Patients were excluded if they were not being treated with chemotherapy and/or radiotherapy. Eligible participants were enrolled between the fourth and twelfth week after 
a cancer diagnosis. The physician had the right to withdraw participants from the study if their health condition no longer allowed them to participate.

\subsection{Nutritional Intervention}

The nutritional intervention aimed at promoting healthy eating behaviors to ensure normal growth and development of the child, weight maintenance during and after treatment, and prevention of long-term health complications. Participants were followed for at least 1 year from the initial nutritional evaluation. Follow-up visits were planned every 2 months, for a total of 6 during the first year. Two registered dieticians (RD) delivered the intervention to their assigned patients. At each visit, they provided individualized nutritional counseling addressing the side effects of cancer treatments, and encouraging changes in eating behaviors, confidence, self-esteem, assertiveness, and self-acceptance. The proposed approach favored repeated exposure to healthy food without pressure to eat and ensuring an eating routine [39-41]. Dietary restrictions and food classifications that induce dichotomous thinking of "good" and "bad" foods were proscribed as these methods have proven to be harmful and counterproductive in children [39,42]. Dietary intake and anthropometric profile were also monitored at each visit, and the RD encouraged the participant and/or parents to set specific dietary goals based on their needs.

The initial nutritional evaluation aimed at establishing the participant's nutritional history and assessing their dietary needs. For this purpose, information on treatment side effects, weight history, and eating habits was gathered. Dietary intakes were collected with a 24-h recall (24H-R) and a 3-day food record that was handed out to be filled at home. Weight, height, waist circumference (WC), mid-upper arm circumference (MUAC), triceps skinfold thickness (TSFT), and subscapular skinfold thickness (SSFT) were measured. A blood test was planned to assess their nutritional status and cardiometabolic health (glucose, insulin, total cholesterol, high density lipoprotein (HDL)-cholesterol, low density lipoprotein (LDL)-cholesterol, triglycerides, glycated hemoglobin, C-reactive protein, and vitamin $\mathrm{D})$.

At follow-up visits, the RD assessed the participant's goal achievement and the need to adjust the nutritional objectives. Dietary intakes were collected with a $24 \mathrm{H}-\mathrm{R}$ and a 3-day food record to be completed at home. Anthropometric measurements were repeated (weight, height, WC, MUAC, TSFT, and SSFT). After one year of nutritional intervention, the need for additional follow-up was discussed with the participant and/or parents and, if necessary, the frequency of appointments was set to their preference. Originally, meetings were planned to be delivered in person. However, between 15 March and 14 September 2020, meetings were conducted by phone due to the COVID-19 pandemic.

\subsection{Participants' Socio-Demographic and Cancer-Related Characteristics}

Socio-demographic and cancer-related characteristics at recruitment were extracted from medical charts and case report forms. Data collected included medical information (diagnosis and diagnosis date), socio-demographic data of participants (age at diagnosis and age at recruitment) and families (parents' marital status \{married/common-law partners or separated/divorced/widower\}, parental education level \{less than high school, high school, college, or university $\}$ and approximative familial gross revenue $\{<\$ 29,999, \$ 30,000-\$ 69,999$, $\$ 70,000-\$ 109,999, \$ 110,000-\$ 150,000$, or $>\$ 150,000\})$. During the nutritional intervention, cancer evolution was documented via medical charts or communication with the healthcare providers. After one year of nutritional intervention, the patient's cancer evolution was categorized as responder or non responder (patient with refractory disease or relapse).

\subsection{Assessment of Nutritional Status and Vitamin D}

Nutritional status at the initial evaluation was determined with BMI calculated as weight $(\mathrm{kg}) /$ height $(\mathrm{m})^{2}$ (for patients aged from 2 to 19 years) or with a weight-for-length $(\mathrm{W} / \mathrm{L})$ ratio (for infants $\leq 2$ years old) [43]. BMI-for-age and $\mathrm{z}$-score of $\mathrm{W} / \mathrm{L}$ ratio were obtained using the Microsoft ${ }^{\circledR}$ Office Excel ${ }^{\circledR}$ tool developed by the British Columbia Chil- 
dren Hospital and the Canadian Pediatric Endocrine Group based on the 2014 version of Growth Charts for Canada [44]. Determination of nutritional status was adapted to match Canada's growth indicators statement [43]. Malnourished patients were determined by having a $\mathrm{z}$-score $<-2.0$ of $\mathrm{W} / \mathrm{L}$ ratio ( $\leq 2$ years of age) and of BMI-for-age ( $>2$ to 19 years old). For infants ( 0 to 2 years old) and children ( 2 to 5 years old), normal weight ( $\geq-2.0$ to $\leq 3.0 \mathrm{z}$-score) and obesity ( $>3.0 \mathrm{z}$-score) were determined using $\mathrm{W} / \mathrm{L}$ ratio and BMI-for-age, respectively. In participants at least 5 years old, z-scores of BMIfor-age $\geq-2.0$ to $\leq 2.0$ were considered normal weight while $>2.0$ were described with obesity $[43,45,46]$. 25-hydroxyvitamin $\mathrm{D}[25(\mathrm{OH}) \mathrm{D}]$ was measured in serum using liquid chromatography-tandem mass spectrometry. Vitamin D status was assessed based on the 2016 consensus report of experts that defines sufficiency: $>50 \mathrm{nmol} / \mathrm{L}$; insufficiency: 30-50 nmol/L; and deficiency: <30 nmol/L [47].

\subsection{Evaluation of Study Feasibility}

Rates of retention (\% participants retained/participants recruited) and exclusion (\% participants excluded/participants recruited) after one year of intervention were calculated. For participants excluded from the study, the duration of the intervention was computed. Participants who remained in the intervention include all participants not formally excluded from the study. The fidelity of intervention delivery was assessed by the elapsed time between cancer diagnosis and initial evaluation. Participants' level of engagement was determined subjectively by the RDs after one year of intervention based on the ease of scheduling appointments and the global interest towards the intervention. Level of engagement was classified as low: participants who showed minimal involvement during visits (no questions asked, not interested in making dietary changes), multiple refusals and/or avoidance of meetings; moderate: participants who attended visits but were passively involved during visits and/or if multiple appointments were required to complete a follow-up (many postponed follow-ups); and high: participants who were actively involved during visits (many questions asked and demonstration of interest in nutritional counseling) and ease of scheduling/conducting follow-up visits. The participation rate of the intervention was computed for each participant by the number of follow-up visits completed / 6 planned). Participants were grouped according to their level of participation, defined as low ( $0-1$ visit); moderate (2-3 visits), and high ( $\geq 4$ visits).

For each visit, attendance was defined as the number of participants who attended a visit divided by the total number of potential participants (i.e., who were still included in the study at each visit) and expressed as a percentage (\% actual/ potential attendance). The completion rate of study measures at each visit (\% performed/ planned) was also computed.

Based on other studies assessing the feasibility of an intervention for children and their parents, the following feasibility criteria were pre-defined:

- Eligibility: $\geq 70 \%$ of patients are eligible for the intervention $[48,49]$.

- Recruitment: $\geq 50 \%$ of patients approached are recruited [50-52].

- Retention: $\geq 75 \%$ of participants are retained in the intervention after one year [49,51].

- Attendance: $\geq 70 \%$ of participants attend the planned visits (initial evaluation and follow-up visits) [50,51].

- Completion of study measures: acceptable if $\geq 70 \%$ of participants complete the measures and feasible if $\geq 85 \%$ of participants do so [48,51].

\subsection{Assessment of Dietary Intakes}

The 24H-R and 3-day food records were analyzed using the web application Nutrific ${ }^{\circledR}$ developed by the Department of Food Science and Nutrition, Université Laval (https:/ / nutrific.fsaa.ulaval.ca, accessed on 11 February 2022) based on the 2010 Canadian Nutrient File. Vitamin supplements and intravenous fluids were not considered in the analysis. Intakes of energy, fat, protein, dietary fiber, sodium, calcium, and vitamins $C$ and $D$ were calculated for each participant. Energy intake was reported as total calories $(\mathrm{kcal})$ and per body weight $(\mathrm{kcal} / \mathrm{kg})$. Fat intake was calculated as gram per body weight $(\mathrm{g} / \mathrm{kg})$ and as 
the contribution of energy expressed in percent (\% energy). Protein intake was computed on $\mathrm{kg}$ of body weight $(\mathrm{g} / \mathrm{kg})$, as a percentage of total energy (\% energy), and as a percentage of the recommended dietary allowance (RDA) based on the Canadian dietary reference intakes (RDI) [53]. Intakes of dietary fiber and nutrients (sodium, calcium, vitamin C, and vitamin D) were adjusted for energy (per $1000 \mathrm{kcal}$ ) and presented as the percentages of the adequate intake (AI) for dietary fiber, of the tolerable upper intake level (UL) for sodium, and the RDA for calcium, and vitamins C and D [53]. The $24 \mathrm{H}-\mathrm{R}$ completed at initial evaluation was used to describe the dietary intake before the intervention. For the postintervention time point, we analyzed all the $24 \mathrm{H}-\mathrm{Rs}$ that were completed (12 \pm 2 months after the initial evaluation).

\subsection{Data Analysis}

Participants' characteristics are described as mean \pm standard deviation (SD), median, and range (min-max) for continuous variables age at recruitment, $\mathrm{z}$-score of $\mathrm{BMI}$ or $\mathrm{W} / \mathrm{L}$ ratio, and serum $25(\mathrm{OH}) \mathrm{D}\}$. Categorial data including socio-demographic characteristics, cancer-related information, and nutritional and vitamin D status are presented as a percentage (\%) of the total of participants. Descriptive statistics were used to report a feasibility assessment by presenting numbers and percentages for retention, abandon, engagement level, attendance, and completion of study measures. Continuous (duration of the intervention, time between diagnosis and initial evaluation) and ordinal variables (participation to follow-up visits (number of completed visits and participation rate) $\}$ are presented as mean \pm SD, median, and range. Feasibility data and participants' characteristics (sociodemographic, cancer-related information, and nutritional status) were compared between participants retained in the intervention and those who were excluded using Pearson's Chi-square or Fisher's exact tests (to assess the relationship between nominal variables) and Mann-Whitney tests (to investigate the differences between continuous variables). Dietary intakes are presented as mean, range (min-max), median, and interquartile range (25th to 75th percentiles). Participants' characteristics and dietary intakes at initial evaluation were also compared according to participation level \{low (0-1 visit), moderate (2-3 visits), or high ( $\geq 4$ visits) \} using Pearson's Chi-square or Fisher's exact tests and Kruskall-Wallis $H$-tests. Analyses were conducted to investigate the impact of the COVID-19 pandemic. Feasibility parameters were compared between participants who completed the intervention before the pandemic and those who were affected by it using Pearson's Chi-square or Fisher's exact tests and Mann-Whitney tests. Dietary intakes were compared between initial evaluation and post-intervention using Wilcoxon or paired sample $t$-tests. Analyses were performed using SPSS version 25.0 (IBM, Armonk, NY, USA). A p-value <0.05 was considered statistically significant.

\section{Results}

\subsection{Recruitment and Description of the Cohort}

During the study period, 147 patients were identified as potential participants for the VIE intervention according to the inclusion and exclusion criteria (Figure 1). Before reaching out to patients and their parents, approval from the healthcare team (attending oncologist and healthcare professionals) was required. Approval was not granted when a patient had serious medical complications or when the family or emotional context was considered too complex $(n=22,15.0 \%)$. For 15 patients $(10.2 \%)$, authorization from the medical team could not be obtained before the limit of the recruitment period (12 weeks after diagnosis). One patient died before the study could be presented. Therefore, a total of 109 patients were first identified to participate in the VIE study. Among them, consent forms were not presented to 3 families as they did not understand/read French and the consent form was only available in French at the time. We were also unable to contact 14 families before the end of the recruitment period. In the end, the study consent form was presented to 92 participants, which represents an eligibility rate of $62.6 \%$ (target for 
success $\geq 70 \%$ ). Informed consent was obtained for 62 patients, corresponding to a $67.4 \%$ recruitment rate (target for success $\geq 50 \%$ ).

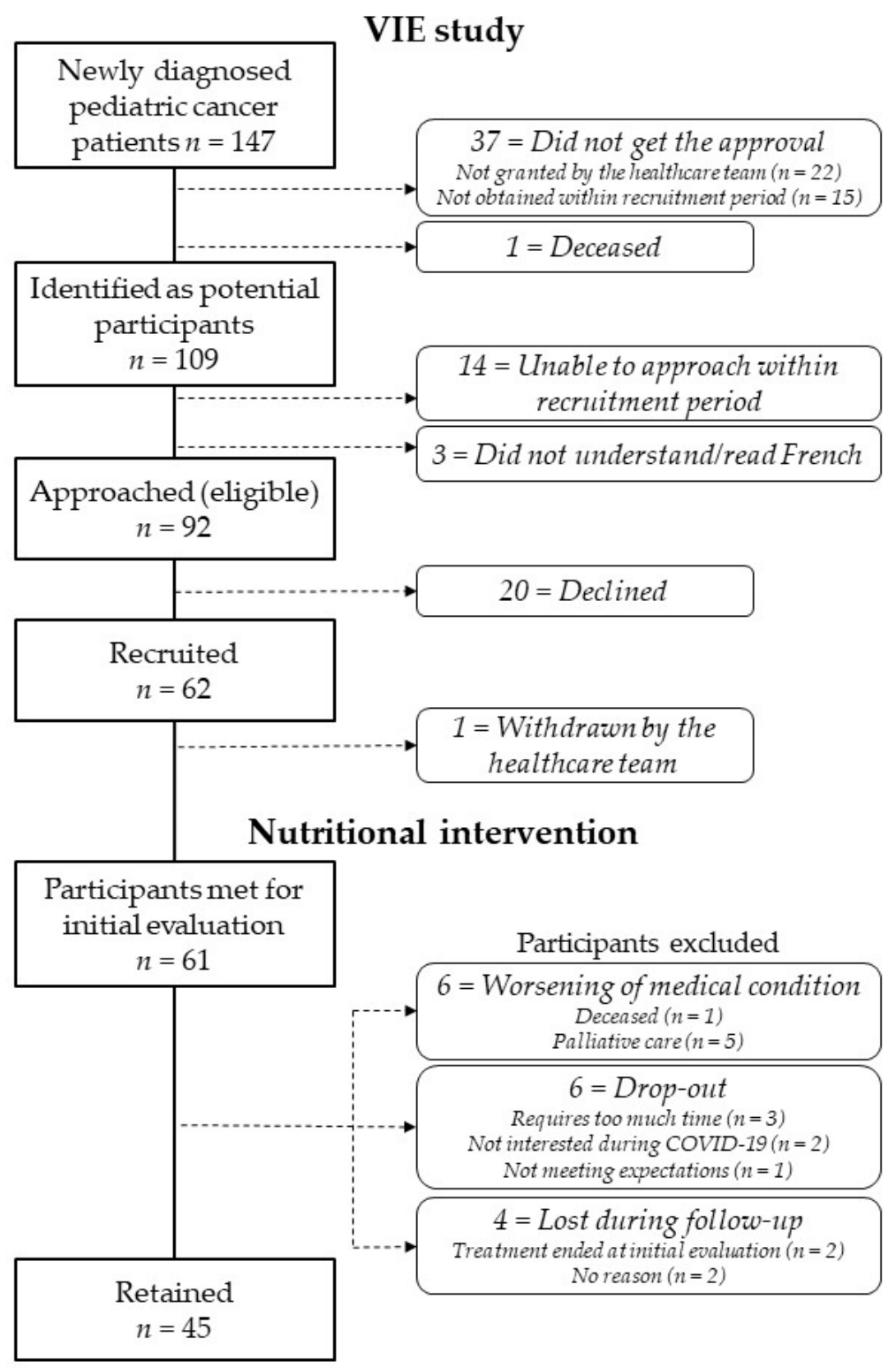

Figure 1. Flow diagram of participants recruited for the nutritional intervention.

The 62 participants that were recruited in the VIE study and their characteristics are described in Table 1. The distribution of participants by sex was almost equal ( $n=32$ boys; $51.6 \%$ ). The mean age at recruitment was 8.5 years (range of 1.4 to 17.3 ) and proportions of preschoolers, children, and adolescents were similar. Most parents were married or common-law partners $(79.2 \%)$, more than half had a university degree $(56.4 \%)$, and more than one-third had an approximated gross family income of less than $\$ 70,000(35.3 \%)$. Overall, 29 patients (46.8\%) were diagnosed with leukemia and during the one-year intervention, 11 participants $(17.7 \%)$ had a refractory response to cancer treatment or a relapse (non responders). At initial evaluation, based on BMI or W/L ratio, no participant was identified as malnourished, whereas $15(24.2 \%)$ were classified as overweight or obese. The mean serum concentration of $25(\mathrm{OH}) \mathrm{D}$ was $59.8 \mathrm{nmol} / \mathrm{L}$ (SD: $24.4 \mathrm{nmol} / \mathrm{L}$ ), and $69.2 \%$ $(n=36)$ of participants had sufficient vitamin D levels whereas 3 patients were classified as deficient $(5.8 \%)$. 
Table 1. Characteristics of participants.

\begin{tabular}{|c|c|}
\hline & Participants \\
\hline Sex, $n(\%)$ & $n=62$ \\
\hline Male & $32(51.6)$ \\
\hline Female & $30(48.4)$ \\
\hline Age at recruitment, year & $n=62$ \\
\hline Mean \pm SD & $8.5 \pm 5.1$ \\
\hline Median (min-max) & $7.4(1.4-17.3)$ \\
\hline Age category, $n(\%)$ & $n=62$ \\
\hline Preschoolers (<5 y.o.) & $22(35.5)$ \\
\hline Children (5 to 12 y.o.) & $22(35.5)$ \\
\hline Adolescents ( $\geq 13$ y.o.) & $18(29.0)$ \\
\hline Marital status, $n(\%)$ & $n=53$ \\
\hline Married/common-law partners & $42(79.2)$ \\
\hline Separated/divorced/widower & $11(20.8)$ \\
\hline Parental education level, $n(\%)$ & $n=55$ \\
\hline Unfinished high school & $2(3.6)$ \\
\hline High school & $13(23.6)$ \\
\hline College & $9(16.4)$ \\
\hline University & $31(56.4)$ \\
\hline Approximated gross family income, $n(\%)$ & $n=51$ \\
\hline$<\$ 29,999$ & $4(7.8)$ \\
\hline$\$ 30,000-\$ 69,999$ & $12(23.5)$ \\
\hline$\$ 70,000-\$ 109,999$ & $17(33.3)$ \\
\hline$\$ 110,000-\$ 150,000$ & $11(21.6)$ \\
\hline$>\$ 150,000$ & 7 (13.7) \\
\hline Cancer diagnosis, $n(\%)$ & $n=62$ \\
\hline Leukemia $^{1}$ & $29(46.8)$ \\
\hline Lymphoma $^{2}$ & $12(19.4)$ \\
\hline Sarcoma ${ }^{3}$ & $10(16.1)$ \\
\hline Other ${ }^{4}$ & $11(17.7)$ \\
\hline Cancer evolution, $n(\%)$ & $n=62$ \\
\hline Responders & $51(82.3)$ \\
\hline Non responders ${ }^{5}$ & $11(17.7)$ \\
\hline BMI or W/L, z-score & $n=61$ \\
\hline Mean \pm SD & $0.3 \pm 1.1$ \\
\hline Median (min-max) & $0.1(-1.9-2.8)$ \\
\hline Nutritional status, $n(\%)$ & $n=61$ \\
\hline Normal & $47(75.8)$ \\
\hline Overweight/Obese & $15(24.2)$ \\
\hline Serum $25(\mathrm{OH}) \mathrm{D}, \mathrm{nmol} / \mathrm{L}$ & $n=52$ \\
\hline Mean \pm SD & $59.8 \pm 24.4$ \\
\hline Median (min-max) & $58.2(22.0-168.0)$ \\
\hline Vitamin D status, $n(\%)$ & $n=52$ \\
\hline Sufficiency & $36(69.2)$ \\
\hline Insufficiency & $13(25.0)$ \\
\hline Deficiency & $3(5.8)$ \\
\hline \multicolumn{2}{|c|}{ 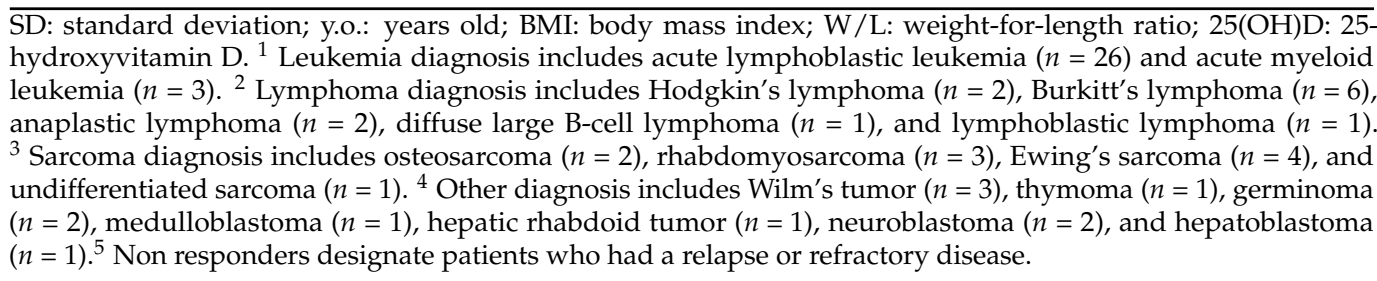 } \\
\hline
\end{tabular}




\subsection{Feasibility of the Intervention}

As illustrated in the flow diagram (Figure 1), the retention rate was $72.6 \%$ (target for success $\geq 75 \%$ ) as 45 participants remained in the intervention (exclusion rate: $27.4 \%$ ). Only one participant was never met by the RDs because of withdrawal from the study prior to the initial evaluation following healthcare providers' recommendation. This participant was excluded from further analyses and subsequent analyses, therefore, there was a total of 61 participants. The reasons for exclusion from the nutritional intervention can be classified as medical and non-medical (Figure 1). For 6 participants, worsening of medical condition resulted in study withdrawal, including one death during the intervention. Study withdrawal following admission in palliative care was recommended by the healthcare providers for 5 participants (two of them died shortly after). For 10 participants, the reasons were non-medical and included the loss of interest in the study because of the time commitment it required $(n=3)$, the context related to the COVID-19 pandemic $(n=2)$, and failure of the intervention to meet expectations $(n=1)$. A total of 4 participants were lost during follow-up as they could not be reached, rendering follow-up visits impossible to schedule.

The duration of the intervention for the 16 participants who were excluded from the study ranged from 0 to 10.8 months (Table 2). Intervention duration was shorter in participants excluded because of study drop-out or loss during follow-up, compared to those excluded due to their medical conditions (median: 4.4 vs. 7.2 months; $p=0.09$ ). For all 6 participants excluded for medical conditions, the cause was cancer related. One patient died suddenly from complications caused by cancer progression and the others were excluded after their transfer to palliative care due to early relapse after treatment $(n=1)$, tumor progression during treatment $(n=3)$, and treatment-refractory cancer $(n=1)$.

Table 2. Feasibility data and comparison between participants retained and excluded.

\begin{tabular}{|c|c|c|c|c|c|}
\hline & & $\begin{array}{l}\text { Participants } \\
\quad n=61\end{array}$ & $\begin{array}{c}\text { Retained } \\
\quad n=45\end{array}$ & $\begin{array}{c}\text { Excluded } \\
\quad n=16\end{array}$ & $p$-Value \\
\hline \multicolumn{2}{|c|}{ Duration of the intervention, months } & & & & - \\
\hline \multicolumn{2}{|c|}{ Mean \pm SD } & $\mathrm{N} / \mathrm{A}$ & $\mathrm{N} / \mathrm{A}$ & $4.6 \pm 3.3$ & \\
\hline \multicolumn{2}{|l|}{ Median (min-max) } & $\mathrm{N} / \mathrm{A}$ & $\mathrm{N} / \mathrm{A}$ & $4.9(0-10.8)$ & \\
\hline \multicolumn{2}{|c|}{$\begin{array}{c}\text { Time between diagnosis and initial } \\
\text { evaluation, weeks }\end{array}$} & & & & 0.34 \\
\hline \multicolumn{2}{|c|}{ Mean \pm SD } & $13.2 \pm 7.1$ & $13.1 \pm 7.7$ & $13.7 \pm 4.9$ & \\
\hline \multicolumn{2}{|l|}{ Median (min-max) } & $11.9(3.1-43.0)$ & $11.7(3.1-43.0)$ & $12.4(5.86-22.0)$ & \\
\hline \multicolumn{2}{|l|}{ Engagement level ${ }^{1}, n(\%)$} & $n=55$ & $n=45$ & $n=10$ & $<0.01$ \\
\hline \multicolumn{2}{|l|}{ Low } & $9(16.4)$ & $4(8.9)$ & $5(50.0)$ & \\
\hline \multicolumn{2}{|l|}{ Moderate } & $15(27.3)$ & $15(33.3)$ & 0 & \\
\hline \multicolumn{2}{|l|}{ High } & $31(56.4)$ & $26(57.8)$ & $5(50.0)$ & \\
\hline \multicolumn{6}{|c|}{ Participation in follow-up visits } \\
\hline \multicolumn{5}{|c|}{ Number of follow-up visits completed, $n$} & $<0.001$ \\
\hline \multicolumn{2}{|c|}{ Mean \pm SD } & $3.2 \pm 1.7$ & $4.0 \pm 1.1$ & $1.2 \pm 1.2$ & \\
\hline \multirow{2}{*}{\multicolumn{2}{|c|}{$\begin{array}{l}\text { Median }(\min -\max ) \\
\text { Rate }^{2} \%\end{array}$}} & $4.0(0-6.0)$ & $4.0(2.0-6.0)$ & $1.0(0-4.0)$ & \\
\hline & & & & & $<0.001$ \\
\hline \multicolumn{2}{|l|}{ Mean \pm SD } & $53.8 \pm 27.6$ & $65.9 \pm 18.5$ & $19.8 \pm 19.5$ & \\
\hline \multicolumn{2}{|l|}{ Median (min-max) } & $66.7(0-100)$ & $66.7(33.3-100)$ & $16.7(0-66.7)$ & \\
\hline & $\begin{array}{l}\text { The differe } \\
\text { using Man } \\
\text { determined } \\
\text { appointmer } \\
\text { the six plan }\end{array}$ & $\begin{array}{l}\text { n feasibility parar } \\
\text { itney } U \text {-tests or } P \\
\text { ectively by the RI } \\
d \text { the global intere }\end{array}$ & $\begin{array}{l}\text { re assessed accord } \\
\text { hi-square test. SD: } \\
\text { ne year of interve } \\
\text { s the intervention. }\end{array}$ & $\begin{array}{l}\text { oarticipants' retenti } \\
\text { rd deviation. }{ }^{1} \text { Lev } \\
\text { ased on the ease of } \\
\text { ntage of follow-up }\end{array}$ & $\begin{array}{l}\text { e interver } \\
\text { gagement } \\
\text { ling follov } \\
\text { mpleted o }\end{array}$ \\
\hline
\end{tabular}

The nutritional intervention was initiated after a mean time of 13.2 weeks from diagnosis (range: 3.1-43.0 weeks) (Table 2). There was no difference in the median time to perform initial evaluation between participants retained in the intervention and those excluded. The engagement level in the intervention was established by the RDs for 55 par- 
ticipants. A majority of participants had a high level of engagement (56.4\%). Overall, the mean number of follow-up visits completed was 3.2, representing a mean rate of $53.8 \%$ of planned visits. Participants excluded from the intervention, compared to those retained, were more likely to have a low level of engagement $(50 \%$ vs. $8.9 \% ; p<0.01)$ and had a lower participation rate (median of $16.7 \%$ vs. $66.7 \%$; $p<0.001$ ). Participants with refractory disease or relapse were less likely to be retained in the intervention compared to treatment responders $(45.5 \%$ vs. $80.0 \% ; p=0.03)$ (Figure 2). Nevertheless, non responders had a similar engagement level compared to participants who were responders to cancer treatment (data not shown). No other association between participants' characteristics and intervention retention was found (data not shown).
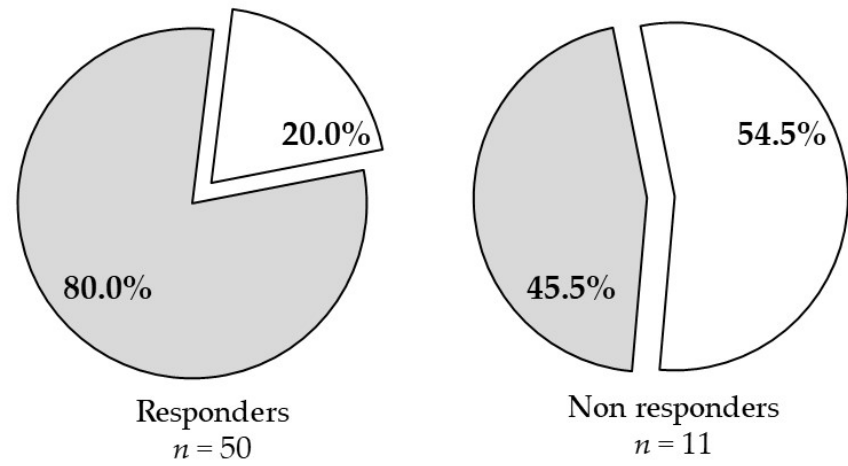

$\square$ Remained in the intervention $\square$ Excluded

Figure 2. Distribution of participants' retention in the intervention based on their cancer evolution. The percentage of patients retained in the intervention and those excluded is illustrated according to participants' cancer evolution (responders vs. non responders). Data were compared using Fisher's exact test.

Table 3 shows the attendance rate at the initial and follow-up visits. Overall, participants attended 258 out of the 362 planned visits, corresponding to a $71.3 \%$ attendance rate (target for success $\geq 70 \%$ ). The attendance rate decreased over the course of the study, ranging from $83.9 \%$ (follow-up visit 1 ) to $48.9 \%$ (follow-up visit 6 ). The average attendance rate was $64.8 \%$ (95\% CI: $54.1-75.4 \%)$. The attendance rate was not different between participants who completed the intervention before the pandemic and those who were affected by it (data not shown).

Table 3. Attendance and completion rates of study measures at visits.

\begin{tabular}{|c|c|c|c|c|c|c|c|c|}
\hline & $\begin{array}{c}\text { Initial } \\
\text { Evaluation }\end{array}$ & $\begin{array}{c}\text { 2-Month } \\
\text { Follow-Up }\end{array}$ & $\begin{array}{c}\text { 4-Month } \\
\text { Follow-Up }\end{array}$ & $\begin{array}{l}\text { 6-Month } \\
\text { Follow-up }\end{array}$ & $\begin{array}{c}\text { 8-Month } \\
\text { Follow-Up }\end{array}$ & $\begin{array}{l}\text { 10-Month } \\
\text { Follow-Up }\end{array}$ & $\begin{array}{l}\text { 12-Month } \\
\text { Follow-Up }\end{array}$ & All Visits \\
\hline \multicolumn{9}{|c|}{ Attendance } \\
\hline $\begin{array}{c}\text { Actual/ } \\
\text { potential } n\end{array}$ & $61 / 62$ & $47 / 56$ & $38 / 55$ & $35 / 51$ & $32 / 47$ & $23 / 46$ & $22 / 45$ & $258 / 362$ \\
\hline Rate (\%) & $(98.4)$ & $(83.9)$ & $(69.1)$ & $(68.6)$ & $(68.0)$ & $(50.0)$ & $(48.9)$ & $(71.3)$ \\
\hline \multicolumn{9}{|c|}{ Completion rates, $n(\%)$} \\
\hline Study measures & $(n=61)$ & $(n=47)$ & $(n=38)$ & $(n=35)$ & $(n=32)$ & $(n=23)$ & $(n=22)$ & Mean $(95 \% \mathrm{CI})$ \\
\hline 3-day food record & $23(37.7)$ & - & - & - & - & - & - & - \\
\hline Blood sample & $55(90.2)$ & - & - & - & - & - & - & - \\
\hline $24 \mathrm{H}-\mathrm{R}$ & $53(86.9)$ & $42(89.4)$ & $31(81.6)$ & $28(80.0)$ & $27(84.4)$ & $20(87.0)$ & $16(72.7)$ & $83.1(78.6-87.6)$ \\
\hline $\mathrm{BMI}$ or $\mathrm{W} / \mathrm{L}$ & $61(100)$ & $45(95.7)$ & $35(92.1)$ & $34(97.1)$ & $30(93.8)$ & $22(95.7)$ & $19(86.4)$ & 94.4 (91.0-97.8) \\
\hline WC & $20(32.8)$ & $7(14.9)$ & $3(7.9)$ & $3(8.6)$ & $3(9.4)$ & $1(4.4)$ & $7(31.8)$ & $15.7(6.3-25.1)$ \\
\hline MUAC & $37(60.7)$ & $19(40.4)$ & $14(36.8)$ & $8(22.9)$ & 7 (21.9) & $5(21.7)$ & $9(40.9)$ & $35.0(23.6-46.4)$ \\
\hline TSFT & $29(47.5)$ & $18(38.3)$ & $11(29.0)$ & $6(17.1)$ & 7 (21.9) & $4(17.4)$ & $7(31.8)$ & $29.0(20.0-38.0)$ \\
\hline SSFT & $23(37.7)$ & $14(29.8)$ & $8(21.1)$ & $4(11.4)$ & $6(18.8)$ & $1(4.4)$ & $5(22.7)$ & $20.8(11.9-29.7)$ \\
\hline
\end{tabular}

Attendance was defined as the number of participants who attended a visit divided by the total number of potential participants. Completion rates of study measures (24H-R, BMI, WC, MUAC, TSFT, and SSFT) were calculated based on participants who attended each visit and expressed as a percentage. CI: confidence intervals; 24H-R: 24-h recall; BMI: body-mass-index; W/L: weight-for-length ratio; WC: waist-circumference; MUAC: mid-upper arm circumference; TSFT: triceps skinfold thickness; SSFT: subscapular skinfold thickness. 
At initial evaluation, completion of the $24 \mathrm{H}-\mathrm{R}$ was found more feasible than of the 3-day food record (Table 3): the low completion rate of this tool (37.7\%) resulted in discontinuing its usage for follow-up visits. Measuring weight and height to calculate BMI and $\mathrm{W} / \mathrm{L}$ were the most feasible anthropometric measures at initial evaluation followed by the MUAC, TSFT, SSFT, and WC. At follow-up visits, the $24 \mathrm{H}-\mathrm{R}$ and BMI or W/L were the two study measures with the highest completion rates, ranging from $72.7 \%$ to $89.4 \%$ and from $86.4 \%$ to $97.1 \%$, respectively. In contrast, WC and SSFT measures had the lowest completion rates (ranging from $4.4 \%$ and $31.8 \%$ ). There was a relationship between the completion of anthropometric measurements (WC, MUAC, TSFT, and SSFT) and age group (children vs. adolescents). At initial evaluation, all four parameters were completed by $55.6 \%$ of adolescents $(n=10 / 18)$ but only by $18.6 \%$ of children $(n=8 / 35)$, which was statistically significant $(p<0.01)$. A supplementary analysis was conducted to assess the relationship between attendance, study measure completion rates, and retention in the intervention (Supplementary Materials Table S1). Overall, no pattern of associations between these variables was observed. We also assessed the relationship between feasibility data (engagement level, participation to follow-up visits, attendance, and completion rates), participants' age category (preschoolers vs. children vs. adolescents), and cancer diagnosis (leukemia vs. lymphoma vs. sarcoma vs. other). No consistent trend was identified between these variables (data not shown).

Participants were grouped according to their level of participation, defined as low (0-1 visit); moderate (2-3 visits); and high ( $\geq 4$ visits) (Table 4 ). Half of the participants were considered to have high participation $(n=31,50.8 \%)$, whereas $31.1 \%$ and $18.0 \%$ were classified as having moderate and low level, respectively. There was a tendency towards a relationship between age category and participation level as $60.5 \%$ of children were classified with high participation compared to $27.5 \%$ of adolescents $(p=0.06)$. Participants with a high level of engagement were more likely to have attended $\geq 4$ follow-up visits (high participation level) compared to those with moderate and low engagement levels $(p=0.001)$. No difference in participation level was found according to participants' socio-demographic profile, cancer-related characteristics, and nutritional status.

Dietary intakes, as assessed at the initial evaluation, were compared between participants according to their participation level (Table 5). Overall, there was no difference in energy and nutrient intake amongst groups, except for proteins, as those with higher participation levels also had a higher percentage of their total energy provided by proteins.

Table 4. Participants' characteristics according to their participation level.

\begin{tabular}{|c|c|c|c|c|}
\hline & \multicolumn{3}{|c|}{ Participation Level } & \multirow[b]{2}{*}{$p$-Value } \\
\hline & $\begin{array}{c}\text { Low } \\
\text { (0-1 visit) } \\
n=11\end{array}$ & $\begin{array}{c}\text { Moderate } \\
\text { (2-3 Visits) } \\
\quad n=19\end{array}$ & $\begin{array}{c}\text { High } \\
\text { ( } \geq 4 \text { Visits) } \\
n=31\end{array}$ & \\
\hline Sex, $n(\%)$ & & & & 0.40 \\
\hline Male & $5(45.5)$ & $8(42.1)$ & $19(61.3)$ & \\
\hline Female & $6(54.5)$ & $11(57.9)$ & $12(38.7)$ & \\
\hline Age at recruitment, year & & & & 0.36 \\
\hline Mean \pm SD & $9.7 \pm 5.7$ & $9.4 \pm 5.2$ & $7.4 \pm 4.9$ & \\
\hline Median (min-max) & $8.9(2.4-17.1)$ & $8.8(1.9-16.3)$ & $5.2(1.3-17.1)$ & \\
\hline Age category, $n(\%)$ & & & & 0.06 \\
\hline Children (<13 y.o.) & $6(54.5)$ & $11(57.9)$ & $26(83.9)$ & \\
\hline Adolescents ( $\geq 13$ y.o.) & $5(45.5)$ & $8(42.1)$ & $5(16.1)$ & \\
\hline Marital status, $n(\%)$ & $n=10$ & $n=16$ & $n=27$ & 0.74 \\
\hline Married/common-law partners & $9(90.0)$ & $12(75.0)$ & $21(77.8)$ & \\
\hline Separated/divorced/widower & $1(9.1)$ & $4(25.0)$ & $6(22.2)$ & \\
\hline
\end{tabular}


Table 4. Cont.

\begin{tabular}{|c|c|c|c|c|}
\hline & \multicolumn{3}{|c|}{ Participation Level } & \multirow[b]{2}{*}{$p$-Value } \\
\hline & $\begin{array}{c}\text { Low } \\
\text { (0-1 visit) } \\
n=11\end{array}$ & $\begin{array}{c}\text { Moderate } \\
\text { (2-3 Visits) } \\
n=19\end{array}$ & $\begin{array}{c}\text { High } \\
(\geq 4 \text { Visits) } \\
n=31\end{array}$ & \\
\hline Parental education level, $n(\%)$ & $n=10$ & $n=16$ & $n=29$ & 0.86 \\
\hline Unfinished high school/high school & $4(40.0)$ & $4(25.0)$ & $7(24.1)$ & \\
\hline College & $1(10.0)$ & $2(12.5)$ & $6(20.7)$ & \\
\hline University & $5(50.0)$ & $10(62.5)$ & $16(55.2)$ & \\
\hline Mean gross family revenue, $n(\%)$ & $n=9$ & $n=14$ & $n=28$ & 0.08 \\
\hline$<\$ 29,999$ & $1(11.1)$ & $1(7.1)$ & $2(7.1)$ & \\
\hline$\$ 30,000-\$ 69,999$ & $1(11.1)$ & $2(14.3)$ & $9(32.1)$ & \\
\hline$\$ 70,000-\$ 109,999$ & $7(77.8)$ & $3(21.4)$ & $7(25.0)$ & \\
\hline$\$ 110,000-\$ 150,000$ & $1(11.1)$ & $4(28.6)$ & $7(25.0)$ & \\
\hline$>\$ 150,000$ & 0 & $4(28.6)$ & $3(10.7)$ & \\
\hline Diagnosis, $n(\%)$ & & & & 0.31 \\
\hline Leukemia & $3(27.3)$ & $9(47.4)$ & $16(51.6)$ & \\
\hline Lymphoma & $2(18.2)$ & $4(21.1)$ & $6(19.4)$ & \\
\hline Sarcoma & $2(18.2)$ & $5(26.3)$ & $3(9.7)$ & \\
\hline Other & $4(36.4)$ & $1(5.3)$ & $6(19.4)$ & \\
\hline BMI or $\mathrm{W} / \mathrm{L}, \mathrm{z}$-score & & & & 1.00 \\
\hline Mean \pm SD & $0.3 \pm 1.1$ & $0.3 \pm 1.3$ & $0.3 \pm 1.1$ & \\
\hline Median (min-max) & $-0.1(-1.0-2.5)$ & $-0.1(-1.9-2.8)$ & $0.1(-1.7-2.3)$ & \\
\hline Nutritional status, $n(\%)$ & & & & 0.92 \\
\hline Normal & $9(81.8)$ & $14(73.7)$ & $25(80.6)$ & \\
\hline Overweight/Obese & $2(18.2)$ & $5(26.3)$ & $7(19.4)$ & \\
\hline Cancer evolution, $n(\%)$ & & & & 0.68 \\
\hline Responders & $8(72.7)$ & $16(84.2)$ & $26(83.9)$ & \\
\hline Non responders ${ }^{1}$ & $3(27.3)$ & $3(15.8)$ & $5(16.1)$ & \\
\hline Engagement level ${ }^{2}, n(\%)$ & $n=7$ & $n=17$ & $n=31$ & 0.001 \\
\hline Low & $5(71.4)$ & $3(17.6)$ & $1(3.2)$ & \\
\hline Moderate & 0 & $7(41.2)$ & $8(25.8)$ & \\
\hline High & $2(28.6)$ & $7(41.2)$ & $22(71.0)$ & \\
\hline
\end{tabular}

The participation level was determined for each participant based on the number of follow-up visits attended and defined as low ( $0-1$ visit); moderate (2-3 visits); and high ( $\geq 4$ visits). The relationships between participation level and characteristics (nominal variables) were evaluated using Pearson's Chi-square or Fisher's exact tests. The differences in continuous variables of participants according to their participation level were assessed using Kruskal-Wallis $H$-test. SD: standard deviation; y.o.: years old; BMI: body mass index; W/L: weight-for-length ratio. Leukemia diagnosis includes acute lymphoblastic leukemia $(n=25)$ and acute myeloid leukemia $(n=3)$. Lymphoma diagnosis includes Hodgkin's lymphoma $(n=2)$, Burkitt's lymphoma $(n=6)$, anaplastic lymphoma $(n=2)$, diffuse large B-cell lymphoma $(n=1)$, and lymphoblastic lymphoma $(n=1)$. Sarcoma diagnosis includes osteosarcoma $(n=2)$, rhabdomyosarcoma $(n=3)$, Ewing's sarcoma $(n=4)$, and undifferentiated sarcoma $(n=1)$ Other diagnosis includes Wilm's tumor $(n=3)$, thymoma $(n=1)$, germinoma $(n=2)$, medulloblastoma $(n=1)$, hepatic rhabdoid tumor $(n=1)$, neuroblastoma $(n=2)$, and hepatoblastoma $(n=1) .{ }^{1}$ Non responders designate patients who had a relapse or refractory disease. ${ }^{2}$ Level of engagement was determined subjectively by the RDs after one year of intervention based on the ease of scheduling appointments and the global interest towards the intervention.

Changes in dietary intake was assessed in 21 participants (Table 6). After a mean time of 12 months (SD: 1.1 month), participants had a lower intake of sodium fmedian (IQR): 1065.3 (950.7-1190.6) $\mathrm{mg} / 1000 \mathrm{kcal}\}$ compared to the initial evaluation $\{1542.5$ (1078.4-1665.6) $\mathrm{mg} / 1000 \mathrm{kcal} ; p=0.03\}$. We also found a trend for a higher intake in vitamin C (median: $366.6 \%$ vs. $98.1 \%$; $p=0.08$ ). 
Table 5. Dietary intakes at initial evaluation according to participation level.

\begin{tabular}{|c|c|c|c|c|}
\hline & \multicolumn{3}{|c|}{ Participation Level } & \multirow[b]{2}{*}{$p$-Value } \\
\hline & $\begin{array}{c}\text { Low } \\
(0-1 \text { Visit) } \\
n=9\end{array}$ & $\begin{array}{c}\text { Moderate } \\
\text { (2-3 Visits) } \\
n=19\end{array}$ & $\begin{array}{c}\text { High } \\
\text { ( } \geq 4 \text { Visits) } \\
n=25\end{array}$ & \\
\hline \multicolumn{5}{|l|}{ Energy } \\
\hline Mean (min-max) & 1976 (767-3040) & 1418 (224-2698) & 1702 (9-3751) & 0.22 \\
\hline $\begin{array}{c}\text { Median (IQR) } \\
\mathrm{Kcal} / \mathrm{kg}\end{array}$ & 2077 (1696-2522) & 1452 (842-2058) & 1508 (1075-2149) & \\
\hline Mean $(\min -\max )$ & 77.3 (19.5-194.0) & $51.4(4.9-115.1)$ & $64.8(0.4-159.5)$ & 0.48 \\
\hline Median (IQR) & $48.8(39.5-112.3)$ & $51.9(27.9-74.4)$ & $50.5(35.2-86.1)$ & \\
\hline \multicolumn{5}{|l|}{ Fat } \\
\hline Mean (min-max) & $3.4(0.9-8.6)$ & $2.0(0.2-4.9)$ & $2.7(0-8.7)$ & 0.40 \\
\hline $\begin{array}{c}\text { Median (IQR) } \\
\text { \% Energy }\end{array}$ & $2.1(1.4-4.8)$ & $2.0(0.8-2.7)$ & $2.2(1.0-3.4)$ & \\
\hline Mean (min-max) & $38.4(27.5-49.4)$ & $35.2(23.6-53.3)$ & $35.4(2.3-56.1)$ & 0.50 \\
\hline Median (IQR) & $38.0(36.9-39.9)$ & $35.1(29.5-40.0)$ & $37.4(31.0-39.5)$ & \\
\hline \multicolumn{5}{|l|}{ Protein } \\
\hline Mean (min-max) & $2.7(0.6-7.8)$ & $2.1(0.1-4.2)$ & $2.8(0-7.5)$ & 0.66 \\
\hline $\begin{array}{c}\text { Median (IQR) } \\
\text { \% Energy }\end{array}$ & $1.6(1.2-3.7)$ & $2.5(1.0-3.1)$ & $2.2(1.4-4.1)$ & \\
\hline Mean (min-max) & $13.5(11.4-16.1)$ & $15.9(5.0-20.3)$ & $16.7(1.0-22.9)$ & 0.02 \\
\hline $\begin{array}{c}\text { Median (IQR) } \\
\text { \% RDA }\end{array}$ & $13.3(12.8-14.2)$ & $16.0(13.9-19.1)$ & $18.1(13.7-19.3)$ & \\
\hline Mean (min-max) & $273.1(67.0-741.9)$ & $218.0(7.2-440.8)$ & $289.0(0-712.1)$ & 0.69 \\
\hline Median (IQR) & $184.1(144.4-354.6)$ & $267.1(107.1-325.0)$ & $232.4(146.8-404.7)$ & \\
\hline \multicolumn{5}{|c|}{ Dietary fiber } \\
\hline Mean (min-max) & $9.8(3.1201321 .3)$ & $8.2(3.4-15.0)$ & $7.6(0-18.0)$ & 0.50 \\
\hline $\begin{array}{c}\text { Median (IQR) } \\
\% \text { AI }\end{array}$ & $9.2(6.6-10.8)$ & $7.7(6.2-10.2)$ & $7.4(5.3-9.4)$ & \\
\hline Mean (min-max) & $88.9(12.3-283.0)$ & $45.1(5.9-92.8)$ & $43.9(0-107.0)$ & 0.05 \\
\hline Median (IQR) & $73.6(58.8-83.7)$ & $50.5(19.8-63.6)$ & $41.5(32.5-56.7)$ & \\
\hline \multicolumn{5}{|c|}{ Sodium } \\
\hline \multicolumn{5}{|c|}{ Energy-adjusted (mg/1000 kcal) } \\
\hline Mean (min-max) & $1305.7(423.2-1976.1)$ & $1373.8(551.5-2781.3)$ & $1609.4(29.9-7390.6)$ & 0.81 \\
\hline \multicolumn{5}{|l|}{$\%$ UL } \\
\hline Mean (min-max) & $129.4(63.3-224.0)$ & $97.9(12.0-240.8)$ & $133.0(0-313.1)$ & 0.20 \\
\hline Median (IQR) & $107.9(71.2-178.5)$ & $79.4(42.9-143.8)$ & $123.7(80.2-165.5)$ & \\
\hline \multicolumn{5}{|c|}{ Calcium } \\
\hline Mean (min-max) & 464.5 (129.6-1016.6) & $657.5(65.1-1392.3)$ & $619.1(44.9-1175.7)$ & 0.34 \\
\hline $\begin{array}{c}\text { Median (IQR) } \\
\text { \% RDA }\end{array}$ & $449.7(285.1-536.5)$ & $637.7(466.3-792.4)$ & $665.8(276.1-875.5)$ & \\
\hline Mean (min-max) & $101.1(7.7-260.4)$ & $92.3(2.5-224.6)$ & $103.0(0-334.3)$ & 0.99 \\
\hline Median (IQR) & $71.9(58.7-124.8)$ & $93.2(46.6-120.8)$ & $71.9(40.0-177.2)$ & \\
\hline \multicolumn{5}{|l|}{ Vitamin $\mathrm{C}$} \\
\hline Mean (min-max) & $59.2(0-132.9)$ & $46.6(1.9-161.4)$ & $81.3(0.3-390.5)$ & 0.56 \\
\hline $\begin{array}{c}\text { Median (IQR) } \\
\text { \% RDA }\end{array}$ & $68.3(22.8-87.3)$ & $29.2(14.0-64.9)$ & $58.2(25.4-99.0)$ & \\
\hline Mean (min-max) & $329.5(0.1-772.6)$ & $251.0(4.9-1379.9)$ & $414.0(0.9-2132.1)$ & 0.52 \\
\hline Median (IQR) & $275.4(154.1-403.5)$ & $101.7(30.9-289.8)$ & $220.5(87.8-508.0)$ & \\
\hline
\end{tabular}


Table 5. Cont.

\begin{tabular}{|c|c|c|c|c|}
\hline & \multicolumn{3}{|c|}{ Participation Level } & \multirow[b]{2}{*}{$p$-Value } \\
\hline & $\begin{array}{c}\text { Low } \\
\text { (0-1 Visit) } \\
n=9\end{array}$ & $\begin{array}{c}\text { Moderate } \\
\text { (2-3 Visits) } \\
n=19\end{array}$ & $\begin{array}{c}\text { High } \\
\text { ( } \geq 4 \text { Visits) } \\
n=25\end{array}$ & \\
\hline \multicolumn{5}{|c|}{ Vitamin D } \\
\hline Mean $(\min -\max )$ & $2.6(0.0-8.8)$ & $3.5(0-10.6)$ & $3.9(0-13.3)$ & 0.22 \\
\hline $\begin{array}{c}\text { Median (IQR) } \\
\text { \% RDA }\end{array}$ & $2.0(1.6-2.5)$ & $2.8(1.1-4.3)$ & $4.1(1.6-4.9)$ & \\
\hline Mean (min-max) & $33.4(0-105.5)$ & $32.8(0-79.8)$ & $38.9(0-101.0)$ & 0.59 \\
\hline Median (IQR) & $31.2(8.0-39.5)$ & $22.6(11.7-48.9)$ & $38.7(22.3-55.3)$ & \\
\hline
\end{tabular}
intake level.

Table 6. Comparison of dietary intake at initial evaluation and post-intervention.

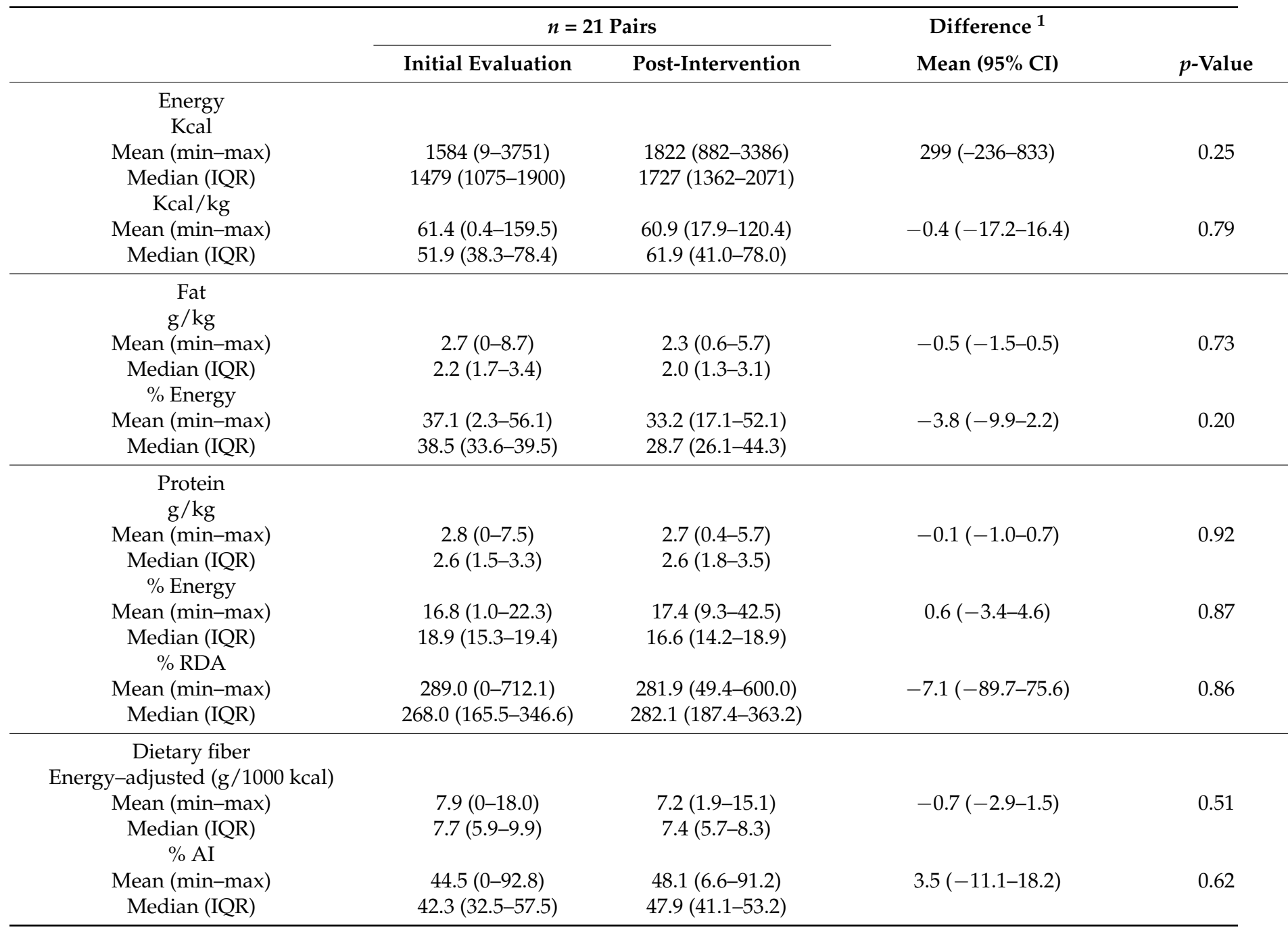


Table 6. Cont.

\begin{tabular}{|c|c|c|c|c|}
\hline & \multicolumn{2}{|c|}{$n=21$ Pairs } & \multirow{2}{*}{$\begin{array}{c}\text { Difference }{ }^{1} \\
\text { Mean }(95 \% \text { CI) }\end{array}$} & \multirow[b]{2}{*}{$p$-Value } \\
\hline & Initial Evaluation & Post-Intervention & & \\
\hline \multicolumn{5}{|c|}{ Sodium } \\
\hline \multicolumn{5}{|c|}{ Energy-adjusted (mg/1000 kcal) } \\
\hline Mean (min-max) & $1612.5(29.9-7390.6)$ & $1078.4(727.7-1403.6)$ & $-564.1(-1193.1-64.9)$ & 0.03 \\
\hline Median (IQR) & $1542.5(1078.4-1665.6)$ & $1065.3(950.7-1190.6)$ & & \\
\hline \multicolumn{5}{|l|}{$\%$ UL } \\
\hline Mean (min-max) & $132.4(0-313.1)$ & $100.1(59.1-206.6)$ & $-32.3(-81.9-17.4)$ & 0.19 \\
\hline Median (IQR) & $109.8(74.9-165.5)$ & $93.5(68.2-114.8)$ & & \\
\hline \multicolumn{5}{|c|}{ Calcium } \\
\hline \multicolumn{5}{|c|}{ Energy-adjusted (mg/1000 kcal) } \\
\hline Mean (min-max) & $614.9(44.9-969.1)$ & $581.2(80.0-1520.2)$ & $-33.7(-181.6-114.3)$ & 0.64 \\
\hline Median (IQR) & $637.7(549.7-773.5)$ & $465.7(349.2-723.7)$ & & \\
\hline \multicolumn{5}{|l|}{$\%$ RDA } \\
\hline Mean (min-max) & $102.8(0-334.3)$ & $96.3(20.5-216.4)$ & $-6.5(-43.8-30.8)$ & 0.79 \\
\hline Median (IQR) & $93.2(64.2-109.8)$ & $76.1(45.7-140.6)$ & & \\
\hline \multicolumn{5}{|c|}{ Vitamin C } \\
\hline \multicolumn{5}{|c|}{ Energy-adjusted (mg/1000 kcal) } \\
\hline Mean $(\min -\max )$ & $70.8(0.3-390.5)$ & $86.8(4.5-268.8)$ & $15.9(-35.0-66.9)$ & 0.36 \\
\hline Median (IQR) & $30.1(16.4-63.5)$ & $63.2(33.6-111.3)$ & & \\
\hline \multicolumn{5}{|l|}{ \% RDA } \\
\hline Mean (min-max) & $292.1(0.9-2132.1)$ & $436.0(16.0-1307.7)$ & $143.9(-80.8-368.7)$ & 0.08 \\
\hline Median (IQR) & $98.1(62.2-317.7)$ & $366.6(149.5-679.9)$ & & \\
\hline \multicolumn{5}{|c|}{ Vitamin D } \\
\hline \multicolumn{5}{|c|}{ Energy-adjusted ( $\mu \mathrm{g} / 1000 \mathrm{kcal})$} \\
\hline Mean (min-max) & $3.7(0-13.3)$ & $4.5(0.3-33.1)$ & $0.7(-2.7-4.2)$ & 1.00 \\
\hline Median (IQR) & $4.0(1.8-4.9)$ & $3.0(0.9-5.1)$ & & \\
\hline \multicolumn{5}{|l|}{ \% RDA } \\
\hline Mean (min-max) & $36.4(0-80.4)$ & $47.9(3.2-300.4)$ & $3.5(-11.1-18.2)$ & 0.95 \\
\hline Median (IQR) & $38.7(20.3-53.0)$ & $35.3(8.7-58.1)$ & & \\
\hline
\end{tabular}

Dietary intakes were evaluated in 21 participants at initial evaluation and post-intervention using 24-h recalls. Differences in mean dietary intakes before and after the intervention were compared using Wilcoxon or pairedsamples $t$-tests. IQR: interquartile range (25th to 75th percentiles); RDA: Recommended Dietary Allowance; AI: Adequate intake; UL: Tolerable upper intake level. ${ }^{1}$ The mean difference in dietary intake of the group was calculated as dietary intake post-intervention-dietary intake at initial evaluation.

\section{Discussion}

The results of this study support the feasibility of conducting a one-year nutritional intervention with a bi-monthly follow-up that promotes healthy eating behaviors and which begins early after the diagnosis of pediatric cancer. Both the intervention recruitment and attendance rates were above the pre-determined targets for success. Although the eligibility $(62.5 \%)$ and retention $(72.6 \%)$ rates were slightly below the established targets of $\geq 70 \%$ and $\geq 75 \%$, we believe that the difference is too modest to conclude that the intervention is not feasible. After one year, $72.6 \%$ of participants were still active in the study, and two-thirds of the scheduled follow-up visits were completed. The BMI or W/L ratio and 24H-R were easier study measures to collect compared to WC, SSFT, and 3-day food records. We also found that participants who did not respond to cancer treatment (had relapsed or refractory disease) were most likely to be excluded from the intervention. Moreover, patients retained in the intervention and those with high participation level ( $\geq 4$ follow-up visits) were more likely to have a high level of engagement. In addition, at initial evaluation, nearly $25 \%$ of participants were overweight or obese and $30.8 \%$ had serum vitamin D levels below $50 \mathrm{nmol} / \mathrm{L}$ indicating a risk of insufficiency for bone health [47]. These results support not only the feasibility of the intervention but also its relevance in a pediatric oncology setting.

Malnutrition (undernutrition and overnutrition) at pediatric cancer diagnosis and during treatment has been associated with worse outcomes, more treatment-related toxi- 
cities, and poor quality of life [17,54-57]. Interventions that promote the adoption or the maintenance of healthy lifestyle habits during treatment may improve patients' nutritional status and dietary intakes. Therefore, in the short term, they could lead to a better prognosis and quality of life, while in the long term, they could help prevent the development of health complications. However, the studies assessing the impact of such nutritional intervention in pediatric cancer have been conducted towards the end of the treatment trajectory, i.e., during the maintenance phase or after therapy [30,32,58]. While limited in number and to children with ALL, these studies have shown little impact on weight gain, even if dietary intakes were improved $[32,33,58]$. It is possible that interventions starting earlier after diagnosis would be more appropriate than those initiated later during treatment or targeting survivors. Here, we describe the feasibility of a nutritional intervention initiated after a median time of 11.9 weeks following diagnosis of pediatric cancer.

From the time of cancer diagnosis, children and adolescents face many challenges that can be detrimental to the development and maintenance of a long-term healthy lifestyle. Preschool age is a critical period in the development of eating habits $[41,59]$. As about half of all childhood cancer diagnoses (0-14 years) occur before the age of 5 [1], and given the impact of antineoplastic treatments on nutritional outcomes, this may negatively impact children's feeding practices [41,60]. In addition, parental attitudes are often modified following the diagnosis of childhood cancer as they tend to be more permissive towards dietary choices and use food as a reward [30,41,61]. Changes in eating habits, sedentary behavior, and weight gain acquired by children and adolescents early in the cancer treatment trajectory may persist after therapy $[30,62,63]$. Thus, researchers and parents expressed the need for interventions to begin early after diagnosis in order to support families with feeding practices that may prevent negative long-term eating habits $[30,41,61]$. However, the timing of initiating such nutritional intervention in different types of pediatric cancer has been poorly explored. Our study did not reveal differences in the time to initiate the intervention from cancer diagnosis between retained and excluded participants. Moreover, the level of participation in the intervention did not differ according to the type of cancer diagnosis. These results support that it is feasible to start a nutritional intervention 4 to 12 weeks after pediatric cancer diagnosis regardless of its type.

It has been proposed that the emotional impact of childhood cancer diagnosis and the acute treatment phase have been identified as barriers to implementing such an early intervention $[30,64,65]$. Accordingly, in our study, the worsening of the medical condition was one of the main reasons for exclusion from the intervention. However, participants identified as non responders to cancer treatment (had relapsed or refractory disease) were not all excluded from the study, as 5 out of 11 remained in the intervention (including 1 deceased). Additionally, the 11 participants who were classified as non responders to cancer treatment had similar engagement and participation levels compared to the other patients. This suggests that the intervention can still be feasible for these participants and that they should not be excluded outright because of an unfavorable medical condition.

Participants excluded from the study for non-medical reasons had a short duration of the active intervention (median: 4.4 months) and a low number of follow-up visits (median: 1 visit; range: $0-3$ ). This indicates that these participants recognized early on that the intervention was not suitable for them and either dropped out from the study or avoided the appointments (lost during follow-up). Two participants dropped out from the intervention due to the COVID-19 pandemic circumstances: the follow-up visits planned at the outpatient clinic were replaced by telephone monitoring.

The attendance rate decreased over time during the one-year intervention, but the COVID-19 pandemic did have a significant impact. In a pilot study designed for parents, six families were recruited to test the feasibility and acceptability of an intervention which consisted of six group information sessions (1 per week) related to overweight and obesity in pediatric cancer survivors [30]. Most of the parents attended at least $75 \%$ of the program, but there was no additional information on the attendance rate for each session; although parents expressed uncertainty about their availability to participate in all six sessions [30]. 
The necessity to attend multiple sessions has been identified as a barrier to participation among parents of pediatric cancer survivors. In a randomized nutritional counseling intervention including 12 children with ALL, the one-year intervention comprising of 12 monthly one-on-one follow-up visits was successfully delivered [66]. However, no specific data on feasibility such as rates of attendance or completion of study measures were documented or reported [66]. Feasibility evaluation, refers to answering the question "can this study be done?" [34,67], has been poorly described in other nutritional intervention studies in pediatric oncology. To the best of our knowledge, our study is the first to address this issue for all types of childhood cancer.

In our study, a lower proportion of adolescents was classified with high participation level ( $\geq 4$ follow-up visits) compared to children. Adolescents with cancer have specific concerns and needs that differ from their younger peers [68]. Nutritional interventions through individual counseling are less effective in adolescents than school-based programs [69]. It is possible that the design of our intervention based on one-on-one visits was less appropriate to stimulate optimal participation in adolescents compared with children and their parents.

Assessing the feasibility of anthropometric measures for nutritional evaluation revealed that WC had the lowest completion rates. Among arm anthropometry parameters, MUAC had the highest completion rate and SSFT the lowest. Logistical challenges may explain this result. While measures were performed in the outpatient clinic, a private room was not always available, making it difficult to take certain measures. Furthermore, some patients were bedridden and wearing only a hospital gown. Therefore, sometimes the measurements that require the patient to stand up to access the body measurement site were not performed to respect the patient's condition and/or privacy. Age was also a determining factor in the completion of anthropometric measurements. Taking anthropometric measurements was found to be more difficult in infants and children because they were often fearful of medical manipulations, especially those involving the caliper used to assess the TSFT and SSFT.

In the context of our study, the $24 \mathrm{H}-\mathrm{R}$ was the best tool to collect dietary intakes. Completion of the 3-day food journals by participants was not successful at the initial visit, thus the tool was later abandoned for follow-up visits. We can speculate that the burden of completing the tool by families was too much early after diagnosis. Next, we did not uncover straightforward relationships between feasibility parameters and participants quality of diet at the initial evaluation. Only the greater protein intakes of patients with high participation level suggest better diet quality for this group. However, these data remain insufficient to draw clear conclusions and further studies are needed to examine a possible association between diet quality and participation in a nutritional intervention in the context of pediatric oncology. Our preliminary assessment of the impact of the intervention suggests that participants slightly improved their diet, with regard to sodium intake. However, it is possible that this is related to other factors, such as fewer side effects of cancer treatment, which could lead to a better diet. Further studies are needed to assess the impact of such intervention on the quality of diet and food intake.

Based on our experience and the results of this study, a number of actions can be taken to improve participation in a nutritional intervention early after a pediatric cancer diagnosis. Confirming the follow-up visits in advance (by phone or email) could help increase attendance rates and participation. Additionally, since adolescents tended to have lower participation levels than their younger peers, we believe that adapting the nutritional intervention to teenagers could improve their involvement and resulting outcomes.

\section{Conclusions}

Our study supports that a one-year nutritional intervention is feasible early after any pediatric cancer diagnosis. Given the potential benefit of promoting healthy lifestyle habits during the acute phase of treatment and in long-term cancer survivors, early nutritional interventions should be considered. Further studies are needed to evaluate the impact of nutritional intervention on eating habits or health outcomes during and after treatment. 
Supplementary Materials: The following supporting information can be downloaded at: https: / / www.mdpi.com/article/10.3390/nu14051024/s1, Table S1: Attendance and study measures completion rates at visits among participants who completed the intervention and those who did not.

Author Contributions: Conceptualization, D.C., S.S., C.L., D.S. and V.M.; Methodology, V.B., J.D. and V.M.; Formal Analysis, V.B. and J.D.; Investigation, V.B., M.N. and I.B.; Data Curation, V.B. and J.D.; Writing-Original Draft Preparation, V.B., J.D. and V.M.; Writing-Review and Editing, V.B., M.N., I.B., C.M., D.C., S.S., C.L., D.S. and V.M.; Visualization, V.B. and V.M.; Supervision, D.S. and V.M.; Project Administration, I.B. and C.M.; Funding Acquisition, D.C., S.S., C.L., D.S. and V.M. All authors have read and agreed to the published version of the manuscript.

Funding: This research was funded by the Fondation Charles-Bruneau, the Fondation CHU SainteJustine, and the Fonds de recherche Québec en santé.

Institutional Review Board Statement: The study was conducted according to the guidelines of the Declaration of Helsinki and approved by the Institutional Review Board of CHUSJ (protocol \#2017-1413; 19 May 2017).

Informed Consent Statement: Informed consent was obtained from all patients and parents/legal guardians involved in the study.

Data Availability Statement: The datasets used and/or analyzed are available from the corresponding author on reasonable request.

Acknowledgments: We thank all the families and the clinical team of the Division of HematologyOncology at CHU Sainte-Justine.

Conflicts of Interest: The authors have no relevant financial or non-financial interests to disclose. The funders had no role in the design of the study; in the collection, analyses, or interpretation of data; in the writing of the manuscript, or in the decision to publish the results.

\section{References}

1. Ellison, L.F.; Xie, L.; Sung, L. Trends in paediatric cancer survival in Canada, 1992 to 2017. Health Rep. 2021, 32, 3-15. [CrossRef]

2. De, P.; Ellison, L.F.; Barr, R.D.; Semenciw, R.; Marrett, L.D.; Weir, H.K.; Dryer, D.; Grunfeld, E. Canadian adolescents and young adults with cancer: Opportunity to improve coordination and level of care. Can. Med. Assoc. 2011, 183, E187-E194. [CrossRef]

3. Oeffinger, K.C.; Mertens, A.C.; Sklar, C.A.; Kawashima, T.; Hudson, M.M.; Meadows, A.T.; Friedman, D.L.; Marina, N.; Hobbie, W.; Kadan-Lottick, N.S.; et al. Chronic health conditions in adult survivors of childhood cancer. New Engl. J. Med. 2006, 355, $1572-1582$. [CrossRef]

4. Hudson, M.M.; Mulrooney, D.A.; Bowers, D.C.; Sklar, C.A.; Green, D.M.; Donaldson, S.S.; Oeffinger, K.C.; Neglia, J.P.; Meadows, A.T.; Robison, L.L. High-risk populations identified in Childhood Cancer Survivor Study investigations: Implications for risk-based surveillance. J. Clin. Oncol. 2009, 27, 2405-2414. [CrossRef]

5. Hoffman, K.E.; Derdak, J.; Bernstein, D.; Reynolds, J.C.; Avila, N.A.; Gerber, L.; Steinberg, S.M.; Chrousos, G.; Mackall, C.L.; Mansky, P.J. Metabolic syndrome traits in long-term survivors of pediatric sarcoma. Pediatr. Blood Cancer 2008, 50, 341-346. [CrossRef]

6. Levy, E.; Samoilenko, M.; Morel, S.; England, J.; Amre, D.; Bertout, L.; Drouin, S.; Laverdière, C.; Krajinovic, M.; Sinnett, D.; et al. Cardiometabolic Risk Factors in Childhood, Adolescent and Young Adult Survivors of Acute Lymphoblastic Leukemia-A Petale Cohort. Sci. Rep. 2017, 7, 17684. [CrossRef]

7. Faber, J.; Wingerter, A.; Neu, M.A.; Henninger, N.; Eckerle, S.; Münzel, T.; Lackner, K.J.; Beutel, M.E.; Blettner, M.; Rathmann, W.; et al. Burden of cardiovascular risk factors and cardiovascular disease in childhood cancer survivors: Data from the German CVSS-study. Eur. Heart J. 2018, 39, 1555-1562. [CrossRef]

8. De Ferranti, S.D.; Steinberger, J.; Ameduri, R.; Baker, A.; Gooding, H.; Kelly, A.S.; Mietus-Snyder, M.; Mitsnefes, M.M.; Peterson, A.L.; St-Pierre, J.; et al. Cardiovascular Risk Reduction in High-Risk Pediatric Patients: A Scientific Statement From the American Heart Association. Circulation 2019, 139, e603-e634. [CrossRef] [PubMed]

9. Children's Oncology Group. Long-Term Follow-Up Guidelines for Survivors of Childhood, Adolescent, and Young Adult Cancers; Version 5.0; Children's Oncology Group: Monrovia, CA, USA.

10. Tonorezos, E.S.; Robien, K.; Eshelman-Kent, D.; Moskowitz, C.S.; Church, T.S.; Ross, R.; Oeffinger, K.C. Contribution of diet and physical activity to metabolic parameters among survivors of childhood leukemia. Cancer Causes Control 2013, 24, 313-321. [CrossRef]

11. Landy, D.C.; Lipsitz, S.R.; Kurtz, J.M.; Hinkle, A.S.; Constine, L.S.; Adams, M.J.; Lipshultz, S.E.; Miller, T.L. Dietary quality, caloric intake, and adiposity of childhood cancer survivors and their siblings: An analysis from the cardiac risk factors in childhood cancer survivors study. Nutr. Cancer 2013, 65, 547-555. [CrossRef] 
12. Bérard, S.; Morel, S.; Teasdale, E.; Shivappa, N.; Hebert, J.R.; Laverdière, C.; Sinnett, D.; Levy, E.; Marcil, V. Diet Quality Is Associated with Cardiometabolic Outcomes in Survivors of Childhood Leukemia. Nutrients 2020, 12, 2137. [CrossRef] [PubMed]

13. Robinson, D.L.; Loman, D.G.; Balakas, K.; Flowers, M. Nutritional screening and early intervention in children, adolescents, and young adults with cancer. J. Pediatr. Oncol. Nurs. 2012, 29, 346-355. [CrossRef] [PubMed]

14. Sacks, N.; Wallace, E.; Desai, S.; Prasad, V.K.; Henry, D.; Guzikowski, V.; Carney, L.N.; Wright, B.B.; Rheingold, S. Oncology, Hematopoietic Transplant, and Survivorship. In The A.S.P.E.N. Pediatric Nutrition Support Core Curriculum; Corkins, M.R., Ed.; American Society for Parenteral and Enteral Nutrition: Silver Spring, MD, USA, 2010; pp. 349-377.

15. Co-Reyes, E.; Li, R.; Huh, W.; Chandra, J. Malnutrition and obesity in pediatric oncology patients: Causes, consequences, and interventions. Pediatr. Blood Cancer 2012, 59, 1160-1167. [CrossRef] [PubMed]

16. Ward, E.; Hopkins, M.; Arbuckle, L.; Williams, N.; Forsythe, L.; Bujkiewicz, S.; Pizer, B.; Estlin, E.; Picton, S. Nutritional problems in children treated for medulloblastoma: Implications for enteral nutrition support. Pediatr. Blood Cancer 2009, 53, 570-575. [CrossRef] [PubMed]

17. Goldstein, G.; Shemesh, E.; Frenkel, T.; Jacobson, J.M.; Toren, A. Abnormal body mass index at diagnosis in patients with Ewing sarcoma is associated with inferior tumor necrosis. Pediatr. Blood Cancer 2015, 62, 1892-1896. [CrossRef] [PubMed]

18. Brinksma, A.; Roodbol, P.F.; Sulkers, E.; Kamps, W.A.; de Bont, E.S.; Boot, A.M.; Burgerhof, J.G.; Tamminga, R.Y.; Tissing, W.J. Changes in nutritional status in childhood cancer patients: A prospective cohort study. Clin. Nutr. 2015, 34, 66-73. [CrossRef] [PubMed]

19. Arpaci, T.; Toruner, E.K.; Altay, N. Assessment of Nutritional Problems in Pediatric Patients with Cancer and the Information Needs of Their Parents: A Parental Perspective. Asia Pac. J. Oncol. Nurs. 2018, 5, 231-236. [CrossRef] [PubMed]

20. Halton, J.M.; Nazir, D.J.; McQueen, M.J.; Barr, R.D. Blood lipid profiles in children with acute lymphoblastic leukemia. Cancer 1998, 83, 379-384. [CrossRef]

21. Moschovi, M.; Trimis, G.; Apostolakou, F.; Papassotiriou, I.; Tzortzatou-Stathopoulou, F. Serum lipid alterations in acute lymphoblastic leukemia of childhood. J. Pediatr. Hematol. Oncol. 2004, 26, 289-293. [CrossRef]

22. Warris, L.T.; van den Akker, E.L.; Bierings, M.B.; van den Bos, C.; Zwaan, C.M.; Sassen, S.D.; Tissing, W.J.; Veening, M.A.; Pieters, R.; van den Heuvel-Eibrink, M.M. Acute Activation of Metabolic Syndrome Components in Pediatric Acute Lymphoblastic Leukemia Patients Treated with Dexamethasone. PLoS ONE 2016, 11, e0158225. [CrossRef]

23. Esbenshade, A.J.; Simmons, J.H.; Koyama, T.; Koehler, E.; Whitlock, J.A.; Friedman, D.L. Body mass index and blood pressure changes over the course of treatment of pediatric acute lymphoblastic leukemia. Pediatr. Blood Cancer 2011, 56, 372-378. [CrossRef] [PubMed]

24. Hingorani, P.; Seidel, K.; Krailo, M.; Mascarenhas, L.; Meyers, P.; Marina, N.; Conrad, E.U.; Hawkins, D.S. Body mass index (BMI) at diagnosis is associated with surgical wound complications in patients with localized osteosarcoma: A report from the Children's Oncology Group. Pediatr. Blood Cancer 2011, 57, 939-942. [CrossRef] [PubMed]

25. Egnell, C.; Ranta, S.; Banerjee, J.; Merker, A.; Niinimäki, R.; Lund, B.; Mogensen, P.R.; Jonsson, Ó.G.; Vaitkeviciene, G.; Lepik, K.; et al. Impact of body mass index on relapse in children with acute lymphoblastic leukemia treated according to Nordic treatment protocols. Eur. J. Haematol. 2020, 105, 797-807. [CrossRef] [PubMed]

26. van Santen, H.M.; Geskus, R.B.; Raemaekers, S.; van Trotsenburg, A.S.P.; Vulsma, T.; van der Pal, H.J.H.; Caron, H.N.; Kremer L.C.M. Changes in body mass index in long-term childhood cancer survivors. Cancer 2015, 121, 4197-4204. [CrossRef]

27. Paul, S.; Pascal, A.; Yves, B.; Camille, V.; Claire, O.; Audrey, C.; Dominique, P.; Marilyne, P.; Stéphane, D.; Justyna, K.; et al. Metabolic syndrome in long-term survivors of childhood acute leukemia treated without hematopoietic stem cell transplantation: An L.E.A. study. Haematologica 2016, 101, 1603-1610. [CrossRef]

28. Schadler, K.L.; Kleinerman, E.S.; Chandra, J. Diet and exercise interventions for pediatric cancer patients during therapy: Tipping the scales for better outcomes. Pediatr. Res. 2018, 8.83, 50-56. [CrossRef]

29. Zhang, F.F.; Kelly, M.J.; Must, A. Early Nutrition and Physical Activity Interventions in Childhood Cancer Survivors. Curr. Obes. Rep. 2017, 6, 168-177. [CrossRef]

30. Stern, M.; Lamanna, J.; Russell, C.; Ewing, L.; Thompson, A.; Trapp, S.; Bitsko, M.; Mazzeo, S. Adaptation of an obesity intervention program for pediatric cancer survivors (NOURISH-T). Clin. Pract. Pediatr. Psychol. 2013, 1, 264-275. [CrossRef]

31. Beaulieu-Gagnon, S.; Bélanger, V.; Marcil, V. Food habits during treatment of childhood cancer: A critical review. Nutr. Res. Rev. 2019, 32, 265-281. [CrossRef]

32. Hill, R.; Hamby, T.; Bashore, L.; Rapisand, S.; Galipp, K.; Heym, K.; Bowman, W.P. Early Nutrition Intervention Attenuates Weight Gain for Pediatric Acute Lymphoblastic Leukemia Patients in Maintenance Therapy. J. Pediatr. Hematol. Oncol. 2018, 40, 104-110. [CrossRef]

33. Zhang, F.F.; Kelly, M.; Du, M.; Welch, J.G.; Santacruz, N.; Rhoades, J.; Kamins, C.L.; Dreyer, Z.; Scheurer, M.E. Early Lifestyle Intervention for Obesity Prevention in Pediatric Survivors of Acute Lymphoblastic Leukemia. Nutrients 2019, 11, 2631. [CrossRef] [PubMed]

34. Orsmond, G.I.; Cohn, E.S. The Distinctive Features of a Feasibility Study: Objectives and Guiding Questions. OTJR Occup. Particip. Health 2015, 35, 169-177. [CrossRef] [PubMed]

35. Thabane, L.; Ma, J.; Chu, R.; Cheng, J.; Ismaila, A.; Rios, L.P.; Robson, R.; Thabane, M.; Giangregorio, L.; Goldsmith, C.H. A tutorial on pilot studies: The what, why and how. BMC Med. Res. Methodol. 2010, 10, 1. [CrossRef] [PubMed] 
36. Arain, M.; Campbell, M.J.; Cooper, C.L.; Lancaster, G.A. What is a pilot or feasibility study? A review of current practice and editorial policy. BMC Med. Res. Methodol. 2010, 10, 67. [CrossRef]

37. Caru, M.; Duhamel, G.; Marcil, V.; Sultan, S.; Meloche, C.; Bouchard, I.; Drouin, S.; Bertout, L.; Laverdiere, C.; Sinnett, D.; et al The VIE study: Feasibility of a physical activity intervention in a multidisciplinary program in children with cancer. Support. Care Cancer 2020, 28, 2627-2636. [CrossRef]

38. Ogez, D.; Bourque, C.J.; Péloquin, K.; Ribeiro, R.; Bertout, L.; Curnier, D.; Drouin, S.; Laverdière, C.; Marcil, V.; Rondeau, É.; et al. Definition and improvement of the concept and tools of a psychosocial intervention program for parents in pediatric oncology: A mixed-methods feasibility study conducted with parents and healthcare professionals. Pilot Feasibility Stud. 2019, 5, 20. [CrossRef]

39. Gibson, E.L.; Kreichauf, S.; Wildgruber, A.; Vögele, C.; Summerbell, C.D.; Nixon, C.; Moore, H.; Douthwaite, W.; Manios, Y. A narrative review of psychological and educational strategies applied to young children's eating behaviours aimed at reducing obesity risk. Obes Rev. 2012, 13 (Suppl. S1), 85-95. [CrossRef]

40. Birch, L.L.; Gunder, L.; Grimm-Thomas, K.; Laing, D.G. Infants' consumption of a new food enhances acceptance of similar foods. Appetite 1998, 30, 283-295. [CrossRef]

41. Fleming, C.A.; Cohen, J.; Murphy, A.; Wakefield, C.E.; Cohn, R.J.; Naumann, F.L. Parent feeding interactions and practices during childhood cancer treatment. A qualitative investigation. Appetite 2015, 89, 219-225. [CrossRef] [PubMed]

42. Jansen, E.; Mulkens, S.; Jansen, A. Do not eat the red food!: Prohibition of snacks leads to their relatively higher consumption in children. Appetite 2007, 49, 572-577. [CrossRef]

43. Secker, D. Promoting optimal monitoring of child growth in Canada: Using the new WHO growth charts. Can. J. Diet. Pract. Res. 2010, 71, e1-e3. [CrossRef] [PubMed]

44. Rodd, C.; Metzger, D.L.; Sharma, A. Extending World Health Organization weight-for-age reference curves to older children. BMC Pediatr. 2014, 14, 32. [CrossRef] [PubMed]

45. Must, A.; Anderson, S.E. Body mass index in children and adolescents: Considerations for population-based applications. Int. J. Obes. 2006, 30, 590-594. [CrossRef] [PubMed]

46. Browne, E.K.; Zhou, Y.; Chemaitilly, W.; Panetta, J.C.; Ness, K.K.; Kaste, S.C.; Cheng, C.; Relling, M.V.; Pui, C.H.; Inaba, H Changes in body mass index, height, and weight in children during and after therapy for acute lymphoblastic leukemia. Cancer 2018, 124, 4248-4259. [CrossRef]

47. Munns, C.F.; Shaw, N.; Kiely, M.; Specker, B.L.; Thacher, T.D.; Ozono, K.; Michigami, T.; Tiosano, D.; Mughal, M.Z.; Mäkitie, O.; et al. Global Consensus Recommendations on Prevention and Management of Nutritional Rickets. J. Clin. Endocrinol. Metab. 2016, 101, 394-415. [CrossRef]

48. Knox, E.; Glazebrook, C.; Randell, T.; Leighton, P.; Guo, B.; Greening, J.; Davies, E.B.; Amor, L.; Blake, H. SKIP (Supporting Kids with diabetes In Physical activity): Feasibility of a randomised controlled trial of a digital intervention for 9-12 year olds with type 1 diabetes mellitus. BMC Public Health 2019, 19, 371. [CrossRef]

49. McPherson, A.C.; Biddiss, E.; Chen, L.; Church, P.T.; de Groot, J.F.; Keenan, S.; King, G.; Lui, T.; Maltais, D.B.; Mérette, C.; et al. Children and Teens in Charge of their Health (CATCH): A protocol for a feasibility randomised controlled trial of solution-focused coaching to foster healthy lifestyles in childhood disability. BMJ Open 2019, 9, e025119. [CrossRef]

50. Fladeboe, K.M.; O’Donnell, M.B.; Barton, K.S.; Bradford, M.C.; Steineck, A.; Junkins, C.C.; Yi-Frazier, J.P.; Rosenberg, A.R. A novel combined resilience and advance care planning intervention for adolescents and young adults with advanced cancer: A feasibility and acceptability cohort study. Cancer 2021, 127, 4504-4511. [CrossRef]

51. Blake, H.; Quirk, H.; Leighton, P.; Randell, T.; Greening, J.; Guo, B.; Glazebrook, C. Feasibility of an online intervention (STAK-D) to promote physical activity in children with type 1 diabetes: Protocol for a randomised controlled trial. Trials 2016, 17, 583. [CrossRef]

52. Samaan, M.C.; Scheinemann, K.; Burrow, S.; Dillenburg, R.F.; Barr, R.D.; Wang, K.W.; Valencia, M.; Thabane, L. Recruitment feasibility to a cohort study of endocrine and metabolic health among survivors of childhood brain tumours: A report from the Canadian study of Determinants of Endometabolic Health in ChIlDrEn (CanDECIDE). BMJ Open 2014, 4, e005295. [CrossRef]

53. Government of Canada. Dietary Reference Intakes Tables. Available online: https://www.canada.ca/content/dam/hc-sc/ migration/hc-sc/fn-an/alt_formats/hpfb-dgpsa/pdf/nutrition/dri_tables-eng.pdf (accessed on 14 October 2021).

54. Orgel, E.; Sposto, R.; Malvar, J.; Seibel, N.L.; Ladas, E.; Gaynon, P.S.; Freyer, D.R. Impact on survival and toxicity by duration of weight extremes during treatment for pediatric acute lymphoblastic leukemia: A report from the Children's Oncology Group. J. Clin. Oncol 2014, 32, 1331-1337. [CrossRef] [PubMed]

55. Joffe, L.; Dwyer, S.; Glade Bender, J.L.; Frazier, A.L.; Ladas, E.J. Nutritional status and clinical outcomes in pediatric patients with solid tumors: A systematic review of the literature. Semin. Oncol. 2019, 46, 48-56. [CrossRef]

56. Loeffen, E.A.; Brinksma, A.; Miedema, K.G.; de Bock, G.H.; Tissing, W.J. Clinical implications of malnutrition in childhood cancer patients-infections and mortality. Support. Care Cancer 2015, 23, 143-150. [CrossRef] [PubMed]

57. Brinksma, A.; Sanderman, R.; Roodbol, P.F.; Sulkers, E.; Burgerhof, J.G.; de Bont, E.S.; Tissing, W.J. Malnutrition is associated with worse health-related quality of life in children with cancer. Support. Care Cancer 2015, 23, 3043-3052. [CrossRef]

58. Moyer-Mileur, L.J.; Ransdell, L.; Bruggers, C.S. Fitness of children with standard-risk acute lymphoblastic leukemia during maintenance therapy: Response to a home-based exercise and nutrition program. J. Pediatr. Hematol. Oncol. 2009, 31, 259-266. [CrossRef]

59. Birch, L.L.; Fisher, J.O. Development of eating behaviors among children and adolescents. Pediatrics 1998, 101, 539-549. [CrossRef] 
60. Green, R.; Horn, H.; Erickson, J.M. Eating Experiences of Children and Adolescents With Chemotherapy-Related Nausea and Mucositis. J. Pediatr. Hematol./Oncol. Nurs. 2010, 27, 209-216. [CrossRef]

61. Williams, L.K.; McCarthy, M.C. Parent perceptions of managing child behavioural side-effects of cancer treatment: A qualitative study. Child. Care Health Dev. 2015, 41, 611-619. [CrossRef] [PubMed]

62. Zhang, F.F.; Rodday, A.M.; Kelly, M.J.; Must, A.; MacPherson, C.; Roberts, S.B.; Saltzman, E.; Parsons, S.K. Predictors of being overweight or obese in survivors of pediatric acute lymphoblastic leukemia (ALL). Pediatr. Blood Cancer 2014, 61, 1263-1269. [CrossRef] [PubMed]

63. Foster, K.L.; Kern, K.D.; Chambers, T.M.; Lupo, P.J.; Kamdar, K.Y.; Scheurer, M.E.; Brown, A.L. Weight trends in a multiethnic cohort of pediatric acute lymphoblastic leukemia survivors: A longitudinal analysis. PLoS ONE 2019, 14, e0217932. [CrossRef]

64. Folta, S.; Chang, W.; Hill, R.; Kelly, M.; Meagher, S.; Bowman, W.P.; Zhang, F.F. Parent and Health Care Provider Perceptions for Development of a Web-Based Weight Management Program for Survivors of Pediatric Acute Lymphoblastic Leukemia: A Mixed Methods Study. JMIR Cancer 2017, 3, 1. [CrossRef]

65. Dolgin, M.J.; Phipps, S.; Fairclough, D.L.; Sahler, O.J.Z.; Askins, M.; Noll, R.B.; Butler, R.W.; Varni, J.W.; Katz, E.R. Trajectories of Adjustment in Mothers of Children with Newly Diagnosed Cancer: A Natural History Investigation. J. Pediatr. Psychol. 2007, 32, 771-782. [CrossRef] [PubMed]

66. Li, R.; Donnella, H.; Knouse, P.; Raber, M.; Crawford, K.; Swartz, M.C.; Wu, J.; Liu, D.; Chandra, J. A randomized nutrition counseling intervention in pediatric leukemia patients receiving steroids results in reduced caloric intake. Pediatr. Blood Cancer 2017, 64, 374-380. [CrossRef] [PubMed]

67. Eldridge, S.M.; Lancaster, G.A.; Campbell, M.J.; Thabane, L.; Hopewell, S.; Coleman, C.L.; Bond, C.M. Defining Feasibility and Pilot Studies in Preparation for Randomised Controlled Trials: Development of a Conceptual Framework. PLoS ONE 2016, 11, e0150205. [CrossRef] [PubMed]

68. Barr, R.D.; Ferrari, A.; Ries, L.; Whelan, J.; Bleyer, W.A. Cancer in Adolescents and Young Adults: A Narrative Review of the Current Status and a View of the Future. JAMA Pediatr. 2016, 170, 495-501. [CrossRef] [PubMed]

69. Lassi, Z.S.; Salam, R.A.; Das, J.K.; Wazny, K.; Bhutta, Z.A. An unfinished agenda on adolescent health: Opportunities for interventions. Semin. Perinatol. 2015, 39, 353-360. [CrossRef] 